\title{
Designing, Fabricating, and Testing Cost Effective Structural Composite for the SSCL Magnets*
}

\author{
F. Nobrega \\ Superconducting Super Cllider Laboratory ${ }^{\dagger}$ \\ 2550 Beckleymeade Ave. \\ Dallas, TX 75237
}

May 1993

"Presented at the Fifth Annual International Symposium on the Super Collider, May 6-8, 1993 San Francisco, CA.

† Operated by the Universities Research Association, Inc., for the U.S. Department of Energy under Contract No. DE-AC35-89ER40486. 


\title{
DESIGNING, FABRICATING, AND TESTING COST EFFECTIVE STRUCTURAL COMPOSITE FOR THE SSCL MAGNETS
}

\author{
Fred Nobrega \\ Superconducting Super Collider Laboratory* \\ 2550 Beckleymeade Avenue, MS 1009 \\ Dallas, TX 75237-3397
}

\section{INTRODUCTION}

Particle accelerators like the Superconducting Super Collider (SSC) use superconducting dipole magnets to bend the particle bunches around the 54-mile ring and superconducting quadrupole magnets to focus the particles. The heart of these magnets is the superconducting niobium-titanium copper cable which carries extremely high current because the internal resistance is zero at liquid helium temperatures. With these high currents, the magnets generate large magnetic fields on the order of 6.7 Tesla.

The superconducting cable is insulated with a wrap of polyimide film on the first layer and a second layer wrap of either a polyimide film with adhesive or a fiberglass epoxy prepreg. The insulated cable is wound into long coils and cured. All coil materials must withstand temperature extremes from $220^{\circ} \mathrm{C}\left(428^{\circ} \mathrm{F}\right)$ to $-269^{\circ} \mathrm{C}\left(-452^{\circ} \mathrm{F}\right)$ at loads as high as $104 \mathrm{MPa}$ (15 ksi). In addition, all magnet components must survive for 25 years with a total radiation dose of $1000 \mathrm{MRad}$. The parts at the end of a coil are used to support and restrain the conductors during magnet energization, The most common end part materials used to date have been G-10 and G-11 fiberglass and epoxy tubes and laminates in NEMA grades and CR type. Developments in polyimides like bismaleimides, copolymers like the newly developed PT resins and advanced epoxy blends like CTD101 and CTD102 are materials of choice for magnet components because of their radiation resistance. An extensive testing program is currently underway by the SSCL to meastic the radiation degradation of these and many other materials.

\section{END PART DESIGN}

End part design begins with a 2D magnetic cross section of the coils. Conductor parameters such as width, keystone angle, mid-thickness and other information are used with program BEND. This Fortran program optimizes conductor geometry to minimize strain and maximize cable bend radius in the coil end region. The numerical output from the

\footnotetext{
* Operated by the Universities Research Association, Inc., for the U. S. Department of Energy under Contract No. DE-AC35-89ER40486.
} 
program BEND defines the surfaces that support the conductor. The keys, spacers, fillers and saddles are machined directly from the programs geometric output.

The minimum strength requirements of the end parts have not been fully characterized. For years, G-10 and G-11 type materials have been used successfully in the Tevatron accelerator at Fermi National Laboratory. However, the radiation requirements for the Supercollider are orders of magnitude higher than the Tevatron. This precludes using a generic epoxy resin system.

The ideal end part totally supports the end turns, is flexible enough to accommodate the uncured cables during the winding process, and after curing the coil assembly, meets the strength and radiation requirements. The mechanical and thermal loads on the end parts during coil curing, collaring and magnet operation are high. During winding, the coil is uncompressed and somewhat larger than the final cured size. A "low" flexural modulus is desirable for the saddle and spacer end parts because all end parts are designed to the final cured size of the coil. The end parts must be flexible enough to accommodate the larger uncured coil. The keys have very high loads during curing and therefore a higher modulus is preferred. The flexural problem with G-10CR was temporarily solved at the SSC by adding slots to the saddles and spacers. During magnet assembly and operation, flexural and compressive strength and coefficient of thermal expansion become the important material parameters.

\section{FABRICATION}

There are several fabrication methods that can be employed for end parts. They include injection, compression and resin transfer molding of thermoplastic and thermoset materials. Use of metal castings, either coated with organic insulators or anodized, is another viable fabrication technique. An additional requirement for metal end parts is that they must be nonmagnetic. Machining solid end parts from G-10 or G-11 tube has been the standard method at the laboratories due to the small quantities of parts required and the high cost of the other fabrication methods.

\section{Injection Molding}

"Injection molding of thermoplastics is a process by which plastic is melted and injected into a mold cavity. Once the melted plastic is in the mold, it cools to a shape that reflectsthe form of the cavity. The resulting form usually is a finishedpart needing no other work before assembly into or used as a finished product."1

Due to the high cost of tooling and low part count, injection molded end parts were machined from injection molded tubes at Fermi. ${ }^{2}$ Three thermoplastics, Torlon 5030, PEEK (polyetheretherketone) and PEK (polyetherketone) all with $30 \%$ glass fiber were investigated. Lack of adhesion between the cured coil and the end part was a problem particularly with Torlon 5030.

\section{Compression Molding}

"The most apparent advantage of compression molding of thermusets is the simple system involved. The material is placed in a heated cavity and is pressurized for the required cure time. Tooling costs are inexpensive because of the simplicity. Fillers and reinforcements are random and lead to fair strength properties. Material is not wasted because of the absence of sprues and runners." 3 
Compression molded end parts using filled epoxy systems were also studied by Fermi. ${ }^{2}$ The study focused primarily on the manufacturing process as opposed to material selection.

\section{Resin Transfer Molding (RTM)}

When producing an intermediate volume of reinforced plastic parts, RTM is a cost effective technique. ${ }^{4}$ Low viscosity resin is injected into a mold at low injection pressures. Typically the mold cavity contains a fiber preform with fiber orientation determined by strength requirements. Compound transfer molding is very similar to RTM, however the resin contains chopped fibers and the compound is injected into the mold. For low and moderate part counts, RTM tooling is more cost effective than injection molding.

Unlike injection molding, where the tooling needs to be made of steel because of the high temperatures and pressures, RTM molds can be made from composite materials for low quantity production runs. Mass cast epoxy tooling is being used to evaluate a phenolic triazine resin, Cryorad by Allied Signal. This resin as with other cyanate ester resins has the ability to be B-staged or undercured into adhesives, laminates and end parts.

\section{TEST RESULTS}

To demonstrate the feasibility of an undercured, conformable end part, The SSC, Grumman Areospace, Allied Signal, and Cooper Composites pooled their expertise in 1991 to make Cryorad end saddles using the RTM process. A sample outer coil was wound and cured. After a thorough visual inspection and coil measurement, the coil was potted and sectioned. The sectioned parts were inspected for conductor insulation damage, conductor placement and compaction, and for voids and defects in the molded part. No voids were found and conductor placement, compaction and insulation were very good. One of the more important goals was also met. The Cryorad end saddle formed or flowed during the curing cycle into a small gap between the last conductor and the shelf which demonstrates the parts will indeed conform to the conductor group. This is important as a coil made entirely of Cryorad or cyanate ester type end parts would provide total and rigid conductor support.

Cryorad end parts and film adhesive were used in model magnet DSA334 and cold tested in September 1992. Masters made of G-10 were used to fabricate the mold cavities. Structural preforms made of S2 glass and milled fibers were used as fillers. The structural preforms were fabricated on a CNC sewing machine. The end parts used the same RTM manufacturing process as the previous years demonstration part. As before, end parts provided the necessary support for the cable during the winding and curing phase coil manufacturing. The magnet did not show any degradation due to the Cryorad end parts, even though the end saddle was only partially cured to $50 \%$ and the winding key was fully cured during coil winding. During the coil cure cycle, the end parts cured further.

Cryorad manufacturing and material costs have been of great concern even though according to Jacobs, ${ }^{3}$ the cost of a given RTM tool can be from 2 to $25 \%$ of the cost of an injection mold tool. As recent as March 1992, Grumman has lowered its price estimate to below $\$ 100$ per benchmark part at production quantities. However, when compared to injection molding of thermoplastics at $\$ 10$ to $\$ 25$ for the same part, more effort is required to lower the cost of the RTM part. It must be remembered that several of the salient features of the cyanate ester thermoset resins mentioned above are not possible with thermoplastics.

\section{FUTURE PLANS}

A coil winding experiment is planned for mid 1993 that uses end parts made of two different materials and processes. One of the materials is an advance epoxy blend and the 
other is a BMI blend. The manufacturing processes used are bulk compression molding and RTM. Results from this experiment and studies completed to date will be used to determine the material selection and manufacturing process for the $\mathrm{BV} 1 \mathrm{C}$ vertical bending dipole magnet.

\section{CONCLUSIONS}

There are several cost effective fabrication methods available for end parts. The resin selected will play a major role in the fabrication method chosen. More development and testing is necessary to develop the optimum end part material and manufacturing process.

\section{REFERENCES}

1. S. Kirkham, Injection molding thermoplastics, in: "Modern Plastics Encyclopedia," McGraw Hill (1990).

2. A. Lipski, et al., Alternate manufacturing processes and materials for the SSC dipole magnet coil end parts, SSCL-146 March (1992).

3. R. Whitesides, Compression and transfer molding, in: "Modern Plastics Encyclopedia," McGraw Hill (1990)

4. K. Jacobs, Resin transfer molding, in: "Modern Plastics Encyclopedia," McGraw Hill (1990). 

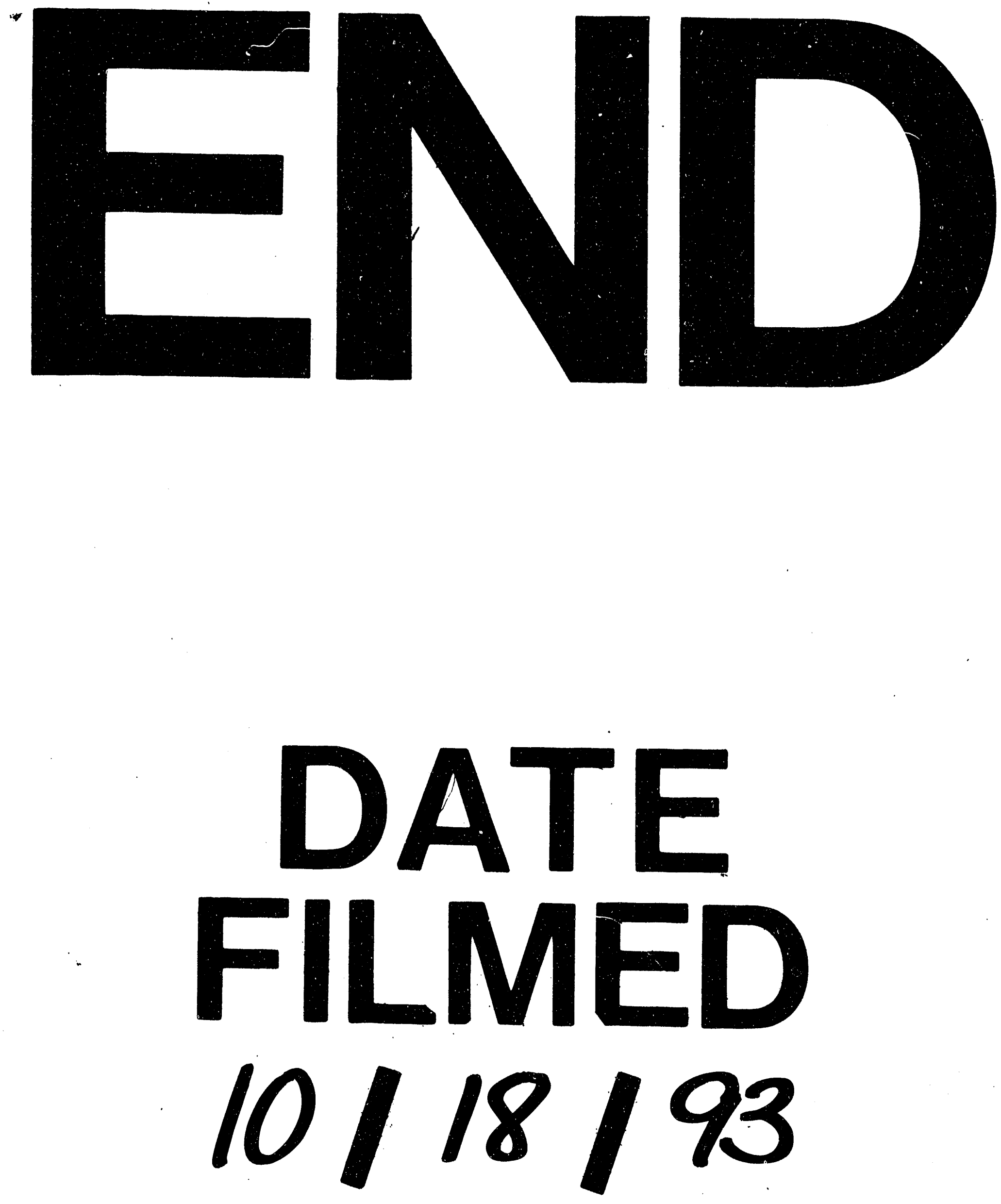
